www.jmscr.igmpublication.org

Impact Factor 5.84

Index Copernicus Value: 83.27

ISSN (e)-2347-176x ISSN (p) 2455-0450

crossref DOI:_https://dx.doi.org/10.18535/jmscr/v5i3.45

\title{
Role of Computerized Tomography in Craniocerebral Trauma
}

\author{
Authors \\ Jagdish Prasad ${ }^{1}$, Chaturbhuj Swarnkar ${ }^{2}$, Naima Mannan ${ }^{3}$, G.L.Meena ${ }^{4}$, \\ Deepak Meena $^{5}$, Deepika Meena ${ }^{6}$, Manish Kumar Meena ${ }^{7}$ \\ ${ }^{1,2,3,4}$ Department of Radiodiagnosis , SP Medical College \& Associate Group of PBM Hospitals, Bikaner \\ ${ }^{5}$ Mahtama Gandhi Dental College Jaipur \\ ${ }^{6}$ Rajasthan Dental College Jaipur \\ ${ }^{7}$ S.N. Medical College, Jodhpur \\ Correspondence Author \\ Dr G.L.Meena \\ Dept of Radiodiagnosis, SP Medical College \& Associate Group of PBM Hospitals, Bikaner INDIA \\ Email: meenabkn@yahoo.co.in, Mobileno.-9413143709
}

\begin{abstract}
Introduction: Traumatic brain injury (TBI) is an extremely common and potentially devastating problem. CT is the single most informative modality in the evaluation of patients with head injury.

Material and Method: This Prospective Study is carried out in patients attending/referred to Sardar Patel Medical College \& Associate Group of Hospitals, Bikaner patients with clinically suspected head injury during the period of March 2016 to Nov 2016. This study was conducted on 100 patients with clinically suspected head injury. They were evaluated with Multi detector Computed Tomography (PHILLIPS BRILLIANS 64 SLICE MDCT SCAN) and findings were correlated with clinical findings wherever applicable.

Results: out of 100 cases 58 cases underwent a conventional skull X-ray prior to CT examination. Skull radiography was found to be slightly better for detecting linear fractures than CT while CT was more specific for depressed fractures. The diagnostic accuracy of CT was $99 \%$ in the present study as compared to the accuracy of clinical examination which was 50\%. The commonest lesion was contusion (39\%) followed by edema (34\%) and subdural hematoma (16\%). $24 \%$ of cases revealed more than one type of lesion (Mixed) while 24\% showed some associated soft tissue injury (Mainly hematoma). Mixed lesions were commonest in the adult age group. All the patients in normal category recovered fully. Among the minor, moderate and major categories the recovery was $70.58 \%, 42.87 \%$ and $28.57 \%$ respectively. An overall mortality of $19 \%$ was noticed. While edema, contusions and hematoma contributed to $31.5 \%$ of total mortality as individual lesions, as mixed lesions they accounted for more than $2 / 3 \mathrm{rds}$ (68.5\%) of mortality. the gap between injury and CT scan increases the chances of recovery decrease and fatality increases.

Conclusion: Computed Tomography is one of the comprehensive diagnostic modality for accurate localisation of the site of injury in acute craniocerebral trauma. The early and timely diagnosis of the precise lesion by CT not only had substantial impact over instituting appropriate treatment and timely surgical intervention but also helped in predicting the ultimate outcome

Keywords: Computed Tomography, Contusions, Hematoma.
\end{abstract}




\section{INTRODUCTION}

Traumatic brain injury (TBI) is an extremely common and potentially devastating problem. Studies have estimated that nearly 1.6 million head injuries occur in the United States each year, resulting in over 50,000 deaths and over 70,000 patients with permanent neurological deficits. ${ }^{1-3}$ TBI accounts for up to $10 \%$ of the health care budget and an estimated annual cost to society of $\$ 30$ billion. ${ }^{4}$ Because prompt proper management of TBI sequelae can significantly alter their course especially within $48 \mathrm{~h}$ of the injury, neuroimaging techniques, which can determine the presence and extent of the injury and guide surgical planning and minimally invasive interventions, play important roles in the acute therapy of $\mathrm{TBI}{ }^{4,5}$ Imaging also can be important in the chronic therapy of TBI, identifying chronic sequelae, determining prognosis, and guiding rehabilitation. Not all head trauma patients require neuroimaging. ${ }^{6}$ Neuroimaging is, of course, costly and can consume scanner time that may be used for patients with other indications. Studies have found that less than $10 \%$ of patients that are considered to have minor head injuries have positive findings on $\mathrm{CT}$ and less than $1 \%$ require neurosurgical intervention. ${ }^{7}$ But this implies that there are still a small number of low risk patients that would benefit from neuroimaging. On the other hand, reducing the number of CT's performed on minor head injury patients even by $10 \%$ may yield more than $\$ 10$ million in savings each year. 8,9

Defining minor versus major head injuries has been problematic. Certain circumstances suggest major injury and almost always merit imaging such as worsening level of consciousness, loss of consciousness for more than $5 \mathrm{~min}$, focal neurological findings, seizure, failure of the mental status to improve over time, penetrating skull injuries, signs of a basal or depressed skull fracture, or confusion or aggression on examination. ${ }^{10}$ However, there is debate over which other circumstances merit imaging. Whereas numerous criteria have been developed, including the New Orleans Criteria ${ }^{11}$ and the
Canadian Head CT rules, ${ }^{12}$ even patients with the complete absence of clinical findings and high risk circumstances have been found to have intracerebral hemorrhage on imaging. ${ }^{13}$

\section{MATERIAL AND METHODS}

Study Area: Department of Radiodiagnosis, Sardar Patel Medical College \& Associated Group of PBM Hospitals, Bikaner.

Study Design: Prospective Study

Study Duration: 6 months (Apr'2016- Oct'2016) SOURCE OF DATA

Data for the study were collected from patients with clinically suspected head injury attending/ referred to the PBM Hospital, Sardar Patel Medical College, Bikaner.

Sampling Technique: Convenience sampling

Sample Size: All clinically suspected head injury patients, eligible as per inclusion criteria, reporting to Department of Radiodiagnosis within study duration.

Method of Data Collection: A descriptive correlational study was conducted on all patients with clinically suspected head injury. They were evaluated with Multi detector Computed Tomography (PHILLIPS BRILLIANS 64 SLICE MDCT SCAN) and findings were correlated with clinical findings wherever applicable.

A complete clinical history of the each patient was taken, which included, age, sex, type of injury and principal presenting complaints. The type of trauma was further classified into Road traffic accidents, falls, Assaults, industrial accidents and miscellaneous. This was followed by general physical examination and detailed examination of the whole abdomen. After initial resuscitation, severity of the cranio-cerebral trauma was graded with the help of "Glasgow Coma Scale" (GCS) as follows.

Grades Scores

- Normal 15

- Mild head injury 13-14

- Moderate head injury 9-12

- Severe head injury $<8$ 


\section{Inclusion Criteria}

1. Patients of all age groups irrespective of their sex with craniocerebral trauma who were advised CT examination after clinical evaluation by treating surgeon.

2. Patients with a history of road traffic accident, fall or assault

3. Glasgow coma scale $<15$.

\section{Exclusion Criteria}

1. Patients with craniocerebral trauma who were hemodynamically unstable.

2. Penetrating injuries.

3. Patients with history of previous cerebrovascular accidents.

4. Patients with previous bleeding disorders.

5. Known diabetic and hypertensive patients receiving anticoagulant therapy.
6. Cranial trauma during childbirth.

7. Pregnant Women.

8. Patients who cannot be followed up.

Data Analysis: The information thus collected was entered into MS Excel worksheet and then analyzed with help of descriptive statistics and appropriate test of significance wherever required.

\section{OBSERVATIONS}

The present study "Role of computerized tomography in craniocerebral trauma" was carried out on 100 patients admitted to P.B.M. Hospital, Bikaner during April, 2016 to October, 2016. All patients were advised CT scanning after clinical examination by the treating surgeon. The following observations were made.

Table 1 Case distribution with respect to Age and Mode of Injury

\begin{tabular}{|l|c|c|c|c|c|c|}
\hline S.N. & Age & RTA & Fall & Assault & Miscellaneous & Total \\
\hline 1. & $0-10$ & 4 & 14 & - & - & 18 \\
\hline 2. & $11-20$ & 10 & 2 & - & 2 & 14 \\
\hline 3. & $21-30$ & 18 & 2 & 5 & 1 & 26 \\
\hline 4. & $31-40$ & 16 & 1 & 6 & - & 23 \\
\hline 5. & $41-50$ & 3 & 1 & - & 2 & 06 \\
\hline 6. & $51-60$ & 2 & 2 & 3 & 2 & 09 \\
\hline 7. & $61 \&$ above & - & 2 & - & 2 & 04 \\
\hline & Total & 53 & 24 & 14 & 9 & 100 \\
\hline
\end{tabular}

Above table shows that RTA was found to be the commonest mode of acute head trauma especially in the $20-40$ years age group but in the pediatric

age group (i.e. $0-10$ years), fall was more common.

Table 2 Incidence of Fractures on Plain X - ray \& CT

\begin{tabular}{|l|c|c|c|c|c|c|}
\hline \multirow{2}{*}{ Modality } & \multirow{2}{*}{ Total No. } & \multirow{2}{*}{$\%$} & \multicolumn{2}{|c|}{ Linear } & \multicolumn{2}{c|}{ Depressed } \\
\cline { 4 - 7 } & & & Total No. & $\%$ & Total No. & $\%$ \\
\hline X ray skull AP/Lateral & $34 / 58$ & 58.6 & 27 & 79.4 & 7 & 20.6 \\
\hline CT scan & $42 / 100$ & 42.0 & 31 & 73.81 & 11 & 26.19 \\
\hline
\end{tabular}

Table No. 2 shows that 58 of the 100 cases underwent a conventional skull X-ray prior to $\mathrm{CT}$ examination. Skull radiography was found to be

slightly better for detecting linear fractures than CT while CT was more specific for depressed fractures.

Table 3 Diagnostic accuracy of CT and clinical judgement

\begin{tabular}{|l|c|c|c|c|c|}
\hline \multirow{2}{*}{ S.N. } & \multirow{2}{*}{ Diagnostic mode } & \multicolumn{2}{|c|}{ Correct diagnosis } & \multicolumn{2}{c|}{ Wrong Diagnosis } \\
\cline { 3 - 6 } & & Total No. & $\%$ & Total No. & $\%$ \\
\hline 1. & Clinical examination & 50 & 50 & 50 & 50 \\
\hline 2. & CT examination & 99 & 99 & 1 & 1 \\
\hline
\end{tabular}

The diagnostic accuracy of CT was $99 \%$ in the wrong diagnosis was suspected to have an anoxic present study as compared to the accuracy of clinical examination which was $50 \%$. The isolated brain injury and no overt lesion was found in the brain parenchyma. 
Table 4 Distribution of lesions on CT scan

\begin{tabular}{|c|c|c|c|}
\hline S.N. & Lesion & No. of Cases & Percentage \\
\hline 1. & Normal* & 29 & 29 \\
\hline 2. & Contusion & 39 & 39 \\
\hline 3. & Edema Gen & 22 & 22 \\
\hline 4. & Edema Focal & 12 & 12 \\
\hline 5. & EDH & 4 & 4 \\
\hline 6. & SDH & 16 & 16 \\
\hline 7. & ICH & 6 & 6 \\
\hline 8. & SAH & 6 & 6 \\
\hline 9. & IVH & 1 & 1 \\
\hline 10. & Pneumocephalus & 3 & 3 \\
\hline 11. & Soft tissue swelling & 24 & 24 \\
\hline 12. & Mixed lesions & 24 & 24 \\
\hline
\end{tabular}

The commonest lesion was contusion (39\%) of lesion (Mixed) while 24\% showed some followed by edema (34\%) and subdural hematoma associated soft tissue injury (Mainly hematoma).

$(16 \%) .24 \%$ of cases revealed more than one type

Table 5 Correlation of clinical severity with CT grades

\begin{tabular}{|c|c|c|c|c|c|c|c|c|c|c|}
\hline \multirow{3}{*}{$\begin{array}{l}\text { Clinical } \\
\text { grade }\end{array}$} & \multirow{3}{*}{ severity } & \multirow{3}{*}{$\begin{array}{c}\text { Total } \\
\text { No. }\end{array}$} & \multicolumn{8}{|c|}{ CT Grade } \\
\hline & & & \multicolumn{2}{|c|}{ Normal } & \multicolumn{2}{|c|}{ Minor } & \multicolumn{2}{|c|}{ Moderate } & \multicolumn{2}{|c|}{ Major } \\
\hline & & & Total & $\%$ & Total & $\%$ & Total & $\%$ & Total & $\%$ \\
\hline I & & 51 & 26 & 51.0 & 14 & 27.0 & 9 & 32.14 & 2 & 8.0 \\
\hline II & & 17 & 2 & 11.7 & 3 & 17.6 & 8 & 28.57 & 4 & 16.0 \\
\hline III & & 32 & 1 & 3.0 & 1 & 3.0 & 11 & 39.28 & 19 & 76.0 \\
\hline
\end{tabular}

It is seen that as the clinical grade of severity respectively in grades II \& III. On the other hand increase, so does the probability of having an abnormal CT scan. This is evidenced by the fact that while more $50 \%$ of grade I cases had a normal CT scan, it decreased to 11.7 and $3 \%$

$76 \%$ cases of grade III severity had lesions classified as major while only $16 \%$ and $8 \%$ of grades II and I respectively did so.

Table 6 Distribution of outcome in different CT categories in acute head trauma

\begin{tabular}{|l|l|l|l|l|l|l|}
\hline \multirow{2}{*}{ S.N. } & \multirow{2}{*}{ CT Category } & Total No. of & \multicolumn{2}{|l|}{ Fully Recovered } & \multicolumn{2}{l|}{ Partly recovered } \\
\cline { 3 - 7 } & & patients & Total & $\%$ & Total & $\%$ \\
\hline 1. & Normal & 29 & 29 & 100 & - & - \\
\hline 2. & Minor & 17 & 12 & 70.58 & 5 & 29.41 \\
\hline 3. & Moderate & 28 & 12 & 42.87 & 16 & 57.14 \\
\hline 4. & Major & 7 & 2 & 28.57 & 5 & 71.42 \\
\hline
\end{tabular}

*=Incl. Focal Neurological Deficit, altered behaviour etc.

All the patients in normal category recovered fully. Among the minor, moderate and major categories the recovery was $70.58 \%, 42.87 \%$ and $28.57 \%$ respectively. On the other hand partial recovery was seen in $71.42 \%$ of major, $57.14 \%$ of moderate and $29.14 \%$ of mild category. Thus chances of partial recovery were more with increasing CT severity.

\section{DISCUSSION}

Data obtained in this study showed that in general, road traffic accidents were the commonest cause of craniocerebral trauma. In adults, they accounted for $57 \%$ of cases but in the pediatric age group, fall was the commonest mode accounting for nearly $75 \%$ of cases. Ghebrehiwet M, Quan LH, Andebirhan T et $\mathrm{al}^{14}$ observed that the commonest causes of head injury were falls $(36.4 \%)$, car accident $(29.0 \%)$, stone injuries (15\%), and bicycle accident (9\%). Abnormal CT 
findings were seen in 60 cases $(54.5 \%)$ and normal CT in $50(45.5 \%)$.

In our study linear fractures occurred more than depressed fractures. CT was observed to be more specific for depressed fractures as compared to linear fractures. Ghebrehiwet M, Quan LH, Andebirhan $\mathrm{T}$ et $\mathrm{al}^{14}$ observed that the most common CT findings were: intra cerebral hematoma $22(20 . \%)$, cerebral contusion or laceration $18(16.4 \%)$, skull fractures $16(6 \%)$, and scalp swelling $3(2.7 \%)$.

In our study linear fractures occurred more than depressed fractures. CT was observed to be more specific for depressed fractures as compared to linear fractures. Imtiaz AM (2016) ${ }^{15}$ included 100 patients in the study. $72 \%$ are males while females constituted only $28 \%$ showing male preponderance in acute TBI. $68 \%$ cases were associated with fracture of the vault. Of the 100 patients, 68 had positive CT scans. All patients with positive CT scan had one or more of 7 findings: headache, vomiting, age over 60 years, drug or alcohol intoxication, deficits in short term memory, physical evidence of trauma and seizures. Study revealed that performing CT in acute TBI, decreased morbidity and mortality and could lead to cost savings. Performing CT in all head injury patients was cost effective.

The diagnostic accuracy of CT examination was 99\% as compared to the clinical accuracy (50\%) in this study. The isolated wrong diagnosis was case no. 31 who was suspected to have anoxic brain injury despite having no overt lesion in his CT examination. Prayer and Rametsteiner ${ }^{16}$ showed that computed tomography (CT) is the primary modality of choice for imaging patients with acute head trauma. Lesions of the soft tissues and bones can be assessed more precisely than with other imaging modalities

The present study indicates that the commonest lesions encountered in cranio - cerebral trauma were contusions $(39 \%)$ followed by oedema (34\% including general as well as focal). Of the hematomas, sub dural hematoma was commonest and resulted in $16 \%$ of cases. Mixed lesions were seen in $24 \%$ of cases. Similar results were observed by Tomar SPS et $\mathrm{al}^{17}$ as they observed that the most common post traumatic consequences found in the study of adults are contusions, brain edema and intracerebral hematomas, while other sequelae such as subarachnoid hematomas, subdural hematomas and extradural hematomas are encountered less.

It was observed in this study that as the clinical grade of severity increases, so does the probability of having an abnormal CT scan. This is evidenced by the fact that while more than $50 \%$ of grade I cases had a normal CT scan, It decreased to $11.7 \%$ and $3 \%$ respectively in grades II and III. On the other hand, $84 \%$ of cases with grade III severity had lesions classified under Major while only $10 \%$ and $7 \%$ of grades II and I respectively did so.

Nayebaghayee $\mathrm{H}$ et al $(2016)^{18}$ observed that regarding clinical condition, of 200 study subjects, $161(80.5 \%)$ had GCS $13-15$ that among those, $45 \%$ had GCS 15. Also, 21 (10.5\%) had GCS ranged 9-12 and $18(9 \%)$ had GCS <8. Of all subjects, 109 (54.5\%) had abnormal CT findings that of them, $77.1 \%$ categorized as mild head injury (GCS 13-15), 11.0\% had moderate head injury (GCS 9-12), and $11.9 \%$ had severe head injury (GCS <9). Also, of those with GCS 15, $41.0 \%$ had abnormal CT scan. Of 109 patients with abnormal CT findings, 36 (33.0\%) underwent surgery that $22(61.1 \%)$ categorized in mild head injury group, $5(13.9 \%)$ categorized in moderate head injury group, and 8 (22.2\%) categorized in severe head injury group. Also, of those with GCS equal to 15, 10 (27.0\%) underwent surgery. Regarding type of lesions in CT scans, the most common type of lesion was epidural hematoma (38.5\%), followed by cerebral contusion (29.4\%), and pneumocephaly (17.4\%).

\section{CONCLUSION}

Computed Tomography is one of the comprehensive diagnostic modality for accurate localisation of the site of injury in acute craniocerebral trauma. The early and timely diagnosis of the precise lesion by CT not only had 
substantial impact over instituting appropriate treatment and timely surgical intervention but also helped in predicting the ultimate outcome.

Funding: No funding sources

Conflict of interest: None declared

Ethical approval: The study was approved by the Institutional Ethics Committee

\section{BIBLIOGRAPHY}

1. Sosin DM, Sniezek JE, Waxweiler RJ. Trends in death associated with traumatic brain injury, 1979 through 1992. Success and failure. JAMA 273: 1778-1780, 1995.

2. Sosin DM, Sniezek JE, Thurman DJ. Incidence of mild and moderate brain injury in the United States, 1991. Brain Inj 10: 47-54, 1996. Traumatic brain injury-Colorado, Missouri, Oklahoma, and Utah, 1990-1993. MMWR Morb Mortal Wkly Rep 46: 8-11, 1997.

3. Hoyt DB, Holcomb J, Abraham E, Atkins J, Sopko G. Working Group on Trauma Research Program Summary Report: National Heart Lung Blood Institute (NHLBI), National Institute of General Medical Sciences (NIGMS), and National Institute of Neurological Disorders and Stroke (NINDS) of the National Institutes of Health (NIH), and the Department of Defense (DOD). J Trauma 57: 410-415, 2004.

4. Pirko I, Fricke ST, Johnson AJ, Rodriguez M, Macura SI. Magnetic resonance imaging, microscopy, and spectroscopy of the central nervous system in experimental animals. NeuroRx 2: 250-264, 2005.

5. Nagy KK, Joseph KT, Krosner SM, Roberts RR, Leslie CL, Dufty K, et al. The utility of head computed tomography after minimal head injury. J Trauma 46: 268270, 1999.

6. Jeret JS, Mandell M, Anziska B, Lipitz M, Vilceus AP, Ware JA, et al. Clinical predictors of abnormality disclosed by computed tomography after mild head trauma. Neurosurgery 32: 9-15, 1993.

7. Miller EC, Holmes JF, Derlet RW. Utilizing clinical factors to reduce head CT scan ordering for minor head trauma patients. J Emerg Med 15: 453-457, 1997.

8. Reinus WR, Wippold FJ 2nd, Erickson KK. Practical selection criteria for noncontrast cranial computed tomography in patients with head trauma. Ann Emerg Med 22: 1148-1155, 1993

9. Moran SG, McCarthy MC, Uddin DE, Poelstra RJ. Predictors of positive CT scans in the trauma patient with minor head injury. Am Surg 60: 533-535, 1994.

10. Duus BR, Lind B, Christensen H, Nielsen $\mathrm{OA}$. The role of neuroimaging in the initial management of patients with minor head injury. Ann Emerg Med 23: 1279-1283, 1994.

11. Haydel MJ, Preston CA, Mills TJ, Luber S, Blaudeau E, DeBlieux PM. Indications for computed tomography in patients with minor head injury. $\mathrm{N}$ Engl J Med 343: 100-105, 2000.

12. Stiell IG, Lesiuk H, Wells GA, Coyle D, McKnight RD, Brison R, et al. Canadian CT head rule study for patients with minor head injury: methodology for phase II (validation and economic analysis). Ann Emerg Med 38: 317-322, 2001.

13. Quayle KS, Jaffe DM, Kuppermann N, Kaufman BA, Lee BC, Park TS, et al. Diagnostic testing for acute head injury in children: when are head computed tomography and skull radiographs indicated? Pediatrics 99: E11, 1997.

14. Ghebrehiwet M, Quan LH, Andebirhan T. The profile of CT scan findings in acute head trauma in Orotta Hospital, Asmara, Eritrea. Journal of Eritrean Medical Association:4-8

15. Imtiaz AM. Trauma Radiology: Importance of Computed Tomography Scans In Acute Traumatic Brain Injury. 
International Journal of Pharmaceutical Sciences and Business Management, Vol.4 Issue. 4, April - 2016, pg. 7-15.

16. Prayer D, Rametsteiner C. Acute head trauma: diagnostic imaging. Wien Med Wochenschr. 2001; 151(21-23):496-501.

17. Singh Tomar S, Bhargava A and Reddy N(2013) Significance of computed tomography scans in head injury. Open Journal of Clinical Diagnostics, 3, 109-114.

18. Nayebaghayee H, Afsharian T. Correlation between Glasgow Coma Scale and brain computed tomography- scan findings in head trauma patients. Asian J Neurosurg 2016;11:46-9. 